УДК 669.17.046:537

І.В. Крикент, д.т.н., доцент

Дніпровський державний технічний університет, м. Кам’янське

\title{
ВИЗНАЧЕННЯ СИЛОВОГО ВПЛИВУ ЗМІННОГО СТРУМУ НА МЕТАЛ У ВАННІ УСТАНОВКИ КІВШ-ПІЧ
}

Робота присвячена теоретичним дослідженням в області позапічної обробки стали. Відзначено доцільність використання математичного моделювання для вивчення процесів, що відбуваються в установках ківи-піч. Запропоновано математичну модель електромагнітного поля в ванні металургійних агрегатів, в яких використовується нагрів металу електричними дугами змінного струму. Ця модель дозволяє розраховувати щільність електромагнітних сил, що діють на рідкий метал в металургійних агрегатах. Наведено результати розрахунку величини електромагнітних сил, що виникають при нагріванні металевого розплаву в ковщі ємністю 60т на установиі ківщ-піч змінного струму. Встановлено, що при використанні змінного струму вплив електромагнітних сил на процес позапічної обробки стали менще, ніж при використанні постійного струму. Наведені ілюстрачії свідчать про те, щя в установках ківщ-піч змінного струму значні електромагнітні сили спостерігаються тільки поблизу поверхні металевої ванни. Показано, що при теоретичних дослідженнях перемішування металу в агрегатах ківш-піч змінного струму, електромагнітні сили можна віднести до малозначущих факторів.

Ключові слова: установка ківш-піч, математична модель, електромагнітні сили, змінний струм, ковшова ванна.

The work is devoted to theoretical research in the field of secondary steel processing. The expediency of using mathematical modeling for studying the processes taking place in the ladlefurnace units is noted. A mathematical model of the electromagnetic field in the pool of metallurgical aggregates is proposed, in which the heating of metal by electric arcs of alternating current is used. This model makes it possible to calculate the density of electromagnetic forces acting on a liquid metal in metallurgical aggregates. The results of calculating the magnitude of the electromagnetic forces of a metal melt arising during heating in a ladle with a capacity of $60 t$ on an installation of an alternating current ladle furnace are presented. It was found that with the use of alternating current, the influence of electromagnetic forces on the secondary treatment process became less than with the use of direct current. The above illustrations show that in the ladle-furnace units of alternating current, considerable electromagnetic forces are observed only near the surface of the metal pool. It is shown that in the case of theoretical studies of metal mixing in aggregates of an alternating current ladle furnace, electromagnetic forces can be attributed to insignificant factors.

Keywords: ladle furnace unit, mathematical model, electromagnetic forces, alternating current, ladle pool.

\section{Постановка проблеми}

Щорічне зростання кількості установок ківш-піч (УКП), що вводяться в експлуатацію на металургійних і машинобудівних підприємствах України та інших країн Європи, збільшення обсягів виробництва сталі з обробкою на УКП, зумовлюють високу актуальність, наукову та прикладну значущість досліджень цього процесу. Вивчення фізичних явищ, відповідальних за якість одержуваного металу, які протікають в ковшовій ванні може сприяти підвищенню ефективності існуючих способів ковшової обробки стали. 3 огляду на високу температуру в установці ківш-піч і поганий доступ даного агрегату для натурних досліджень, одним з основних інструментів вивчення явищ, що протікають в УКП, є математичне моделювання. Оскільки процес доведення металу на установках ківш-піч вимагає ретельного перемішування розплаву, становить практичний інтерес дослідження впливу силових фактів, що діють в рідкому металі, на гідродинамічну обстановку в ванні УКП. Як було відзначено в [1], крім бульбашок газу, що вдувається через донну фурму, істотний вплив на формування складного руху системи газ - металевий розплав мають електромагнітні сили, обумовлені взаємодією електричного струму 3 
власним магнітним полем. Теоретичне дослідження впливу даного чинника на динаміку рідкого металу вимагає створення математичних моделей електромагнітного поля і об'ємних сил, які породжується ним у металевому розплаві, для різних видів дугових модулів, що застосовуються в УКП.

\section{Аналіз останніх досліджень та публікацій}

У сучасній науково-технічній літературі $є$ досить багато інформації про дослідження гідродинаміки рідкого металу в металургійних агрегатах, що використовують дугове нагрівання (установках ківш-піч і сталеплавильних печах), методами математичного моделювання. У деяких роботах враховується вплив електромагнітних сил на рух розплаву [2-11]. При цьому для визначення розподілу струму і об'ємної щільності електромагнітних сил в металі, що обробляється, застосовуються як аналітичні, так і чисельні методи. Застосування останніх дозволило авторам робіт $[2-4,10,11]$ врахувати взаємозв'язок електричних процесів в дуговому розряді і металевої ванні, що позитивно позначається на адекватності моделі і точності розрахункових результатів. До відносних недоліків чисельних методів математичного моделювання можна віднести значний обсяг обчислень. Слід зазначити, що у всіх згаданих роботах використовуються математичні моделі електромагнітних полів, що створюються в рідкій фазі однією дугою постійного струму. Для 3-х дугових модулів нагріву, що використовують 3-х фазний змінний струм, вплив електромагнітного фактора на процес обробки металу не враховується через відсутність відповідних математичних моделей. 3 огляду на цю обставину, а також той факт, що більшість потужних установок ківш-піч, що вводяться в експлуатацію на металургійних підприємствах України та інших країн оснащені дуговими модулями нагріву змінного струму, розробка математичних моделей електромагнітних процесів в таких агрегатах $\epsilon$ досить актуальною.

\section{Мета роботи}

Метою роботи є побудова розрахунково-аналітичної моделі, що дозволяє розраховувати розподіли електромагнітного поля і об'ємної щільності електромагнітних сил, що виникають в металевих ваннах електрометалургійних агрегатів (зокрема, УКП), при нагріванні розплаву 3-х дуговим модулем змінного струму.

\section{Виклад основного матеріалу}

Поле електромагнітних сил (е.м.с.), що діють на розплав в УКП змінного струму, можна наближено розрахувати виходячи з аналітичного рішення задачі розподілу щільності струму i магнітного поля в об'ємі ковшової ванни. Реальні геометричні розміри області анодної прив'язки дуги при цьому ігноруються. Як було показано в [6], такий підхід до розрахунку електромагнітних сил в однодуговій установці постійного струму забезпечує досить високу точність моделювання силового поля.

При використанні трифазної схеми живлення УКП в агрегаті діють одночасно три дугові розряди. Кожна дуга горить між графітовим катодом, підключеним до однієї з фаз живильного трансформатора, і поверхнею металевої ванни (анодом), підключеної до нульової точки джерела живлення. Отже, на поверхні металу мають місце три зони вводу змінного струму, які ми будемо вважати точковими. У такій ситуації векторні поля щільності струму і магнітної індукції необхідно розглядати як результат суперпозиції (накладення) відповідних фізичних полів, що створюються трьома струмами, які підводяться до поверхні металевого розплаву в різних точках [12].

Перш за все, розглянемо задачу розтікання струму від одного точкового джерела, що діє в деякій точці $\left(x=x_{1}^{0}, y=y_{1}^{0}, z=0\right)$ на поверхні $z=0$ напівбезкінечної металевої ванни. Слід зазначити, що розміри ванни УКП цілком дозволяють вважати ії напівбезкінечною. У разі використання запропонованої моделі для дослідження фізичних процесів у відносно мілких ваннах дугових сталеплавильних печей, обмеженість їх розміру по глибині може бути врахована за допомогою фіктивних джерел струму $[13,14]$. У локальній сферичної системі координат, центр якої збігається з точкою введення струму $\left(x_{1}^{0}, y_{1}^{0}, 0\right)$, будемо мати:

$$
\vec{J}_{1}=\frac{I_{1} \vec{e}_{R}}{2 \pi R_{1}^{2}} .
$$


тут: $\vec{J}_{1}-$ вектор щільності струму, $I_{1}-$ сила струму, $R_{1}-$ радіальна координата, $\vec{e}_{R}-$ одиничний вектор, спрямований уздовж радіальної координати.

В даному випадку величина $R_{1}$ визначається наступним чином:

$$
R_{1}=\sqrt{\left(x-x_{1}^{0}\right)^{2}+\left(y-y_{1}^{0}\right)^{2}+z^{2}} .
$$

3 урахуванням (2) вираз (1) для розрахунку щільності струму можна переписати для декартової системи координат,центр якої знаходиться га поверхні металевої ванни:

$$
\overrightarrow{J_{1}}=\frac{I_{1}\left(\cos \alpha_{x} \cdot \vec{e}_{x}+\cos \alpha_{y} \cdot \vec{e}_{y}+\cos \alpha_{z} \cdot \vec{e}_{z}\right)}{2 \pi R_{1}^{2}},
$$

де $\alpha_{x}, \alpha_{y}$ и $\alpha_{z}-$ кути між осями $x, y, z$ і радіус - вектором $R_{1}$ відповідно; $\vec{e}_{x}, \vec{e}_{y}$ и $\vec{e}_{z}-$ базисні вектори декартової системи координат.

Визначивши значення напрямних косинусів для довільної точки $(x, y, z)$ через декартові координати останньої, можемо привести формулу для обчислення вектора $\vec{J}_{1}$ до наступного вигляду:

$$
\vec{J}_{1}=\frac{I_{1}\left[\left(x-x_{1}^{0}\right) \vec{e}_{x}+\left(y-y_{1}^{0}\right) \vec{e}_{y}+z \vec{e}_{z}\right]}{2 \pi R_{1}^{3}} .
$$

Щільність струму $\vec{J}_{n}$, що створюється в довільній точці металевої ванни будь-якою 3 трьох дуг, за аналогією з виразом (4), може бути представлена в наступній компактній формі

$$
\vec{J}_{n}=\frac{I_{n}\left(\tilde{x}_{n} \vec{e}_{x}+\tilde{y}_{n} \vec{e}_{y}+z \vec{e}_{z}\right)}{2 \pi R_{n}^{3}}
$$

де $n=1,2,3$ - номер дуги; $R_{n}=\sqrt{\left(\tilde{x}_{n}\right)^{2}+\left(\tilde{y}_{n}\right)^{2}+z^{2}}, \tilde{x}_{n}=x-x_{n}^{0}, \tilde{y}_{n}=y-y_{n}^{0} ; I_{n}-$ струм, а $x_{n}^{0}$ і $y_{n}^{0}$ - декартові координати анодної плями даної дуги.

Результуюча щільність струму в будь-якій точці ванни визначається суперпозицією:

$$
\vec{J}=\sum_{n=1}^{3} \vec{J}_{n} .
$$

При використанні трифазної схеми живлення УКП струми $I_{n}$ зміщені відносно один одного по фазі на $2 \pi / 3$. Інформацію про фази струмів (а також і інших електричних величин) в ланцюгах змінного струму найзручніше враховувати методом комплексних амплітуд [15]. Даний метод передбачає представлення $I_{n}$ в формі комплексних чисел. Якщо застосовується симетрична схема живлення з рівномірним завантаженням трьох фаз, то абсолютні значення амплітуд струмів у всіх трьох дугах однакові і величини $I_{n}(n=1,2,3)$ можна визначити наступним чином:

$$
I_{1}=A(1+0 i), \quad I_{2}=A\left(-\frac{1}{2},+\frac{\sqrt{3}}{2} i\right), I_{3}=A\left(-\frac{1}{2},+\frac{\sqrt{3}}{2} i\right),
$$

де $A$ - модуль амплітудного значення струму в будь-якій з трьох дуг, $i$ - уявна одиниця $(i=\sqrt{-1})$.

Для обчислення е.м.с., що діють на рідкий метал, необхідно також визначити розподіл вектора магнітної індукції в ванні УКП. Як відомо, для парамагнітних середовищ магнітна індукція $\vec{B}$ однозначно визначається напруженістю магнітного поля $\vec{H}$ :

$$
\vec{B}=\mu_{0} \vec{H},
$$

де $\mu_{0}=4 \pi \cdot 10^{-7} \Gamma \mathrm{H} / \mathrm{M}-$ універсальна магнітна стала.

Згідно з результатами, отриманими нами раніше в [6], напруженість магнітного поля, яку створює струмом $I_{1}$, в локальній циліндричній системі координат 3 центром в точці $\left(x_{1}^{0}, y_{1}^{0}, 0\right)$ описується наступною залежністю:

$$
H_{\varphi 1}=\frac{I_{1}}{2 \pi \tilde{r}_{1}}\left(1-\frac{z}{\sqrt{\tilde{r}_{1}^{2}+z^{2}}}\right)
$$


де $H_{\varphi 1}$ - кутова складова вектора напруженості магнітного поля (інші компоненти вектора $\vec{H}$ в даному випадку дорівнюють нулю); $\tilde{r}_{1}=\sqrt{\tilde{x}_{1}^{2}+\tilde{y}_{1}^{2}}-$ радіальна координата в локальній циліндричній системі координат, а $\tilde{x}_{1}=x-x_{1}^{0}$ и $\tilde{y}_{1}=y-y_{1}^{0}-$ локальні декартові координати точки введення струму $I_{1}$.

Спроектувавши кутову складову вектора напруженості магнітного поля на осі $x$ i $y$ отримаємо:

$$
\vec{H}_{1}=\frac{I_{1}}{2 \pi \tilde{r}_{1}}\left(1-\frac{z}{\sqrt{\tilde{r}_{1}^{2}+z^{2}}}\right)\left(-\frac{\tilde{y}_{1}}{\tilde{r}_{1}} \vec{e}_{x}+\frac{\tilde{x}_{1}}{\tilde{r}_{1}} \vec{e}_{y}\right) .
$$

Напруженість магнітного поля, що створюється в ванні УКП змінного струму будь дугою $з$ номером $n$, також може бути обчислена за формулою, аналогічною (9).

$$
\vec{H}_{n}=\frac{I_{n}}{2 \pi \tilde{r}_{n}}\left(1-\frac{z}{\sqrt{\tilde{r}_{n}^{2}+z^{2}}}\right)\left(-\frac{\tilde{y}_{n}}{\tilde{r}_{n}} \vec{e}_{x}+\frac{\tilde{x}_{n}}{\tilde{r}_{n}} \vec{e}_{y}\right),
$$

де $\widetilde{r_{n}}=\sqrt{\tilde{x}_{n}^{2}+\tilde{y}_{n}^{2}}$, а $\tilde{x}$ і $\tilde{y}$ мають таке ж значення, що і вище.

Результуюча напруженість магнітного поля, що створюється в установці струмами трьох дугових розрядів, легко обчислюється у вигляді наступної суми:

$$
\vec{H}=\sum_{n=1}^{3} \vec{H}_{n} .
$$

Оскільки струми $I_{n} \in$ комплексними величинами, під вектором напруженості магнітного поля $\vec{H}$, в даному випадку, слід розуміти його комплексну амплітуду.

Очевидно, що дана методика розрахунку щільності струму і напруженості магнітного поля в металевому розплаві може бути застосовна для будь-якого числа електричних дуг, підключених до багатофазних джерела живлення.

Взаємодія струму, який протікає через метал, що обробляється, з магнітним полем призводить до появи е.м.с. При використанні трифазної схеми живлення УКП щільність струму, магнітна індукція і е.м.с., що діють на метал, циклічно змінюються з частотою змінного струму. $\mathrm{У}$ той же час відносно інертні процеси динаміки рідкої фази визначаються усередненим по періоду змінного струму значенням силового поля. В якості такого виступає середньоінтегральне за часом значення вектора щільності електромагнітної сили $\vec{f}$ :

$$
\vec{f}=\frac{1}{T} \int_{0}^{T} \vec{f}_{t} d t=\frac{\omega}{2 \pi} \int_{0}^{2 \pi / \omega} \vec{f}_{t} d t
$$

де $T=2 \pi / \omega-$ період змінного струму, $\omega-$ циклічна частота струму в мережі живлення $(\omega=2 \pi \cdot 50), \vec{f}_{t}$ - миттєве значення щільності е.м.с., $t$ - часова координата.

Оскільки миттєве значення щільності пондеромоторної сили $\vec{f}_{t} \epsilon$ векторним добутком миттєвих значень векторів щільності струму і магнітної індукції, можемо записати:

$$
\vec{f}_{t}=\mu_{0} \vec{J}_{t} \times \vec{H}_{t}
$$

Відповідно до застосовуваного нами метода комплексних амплітуд, миттєве значення щільності струму $\overrightarrow{J_{t}}$ визначається як дійсна частина комплексної функції:

$$
\vec{J}_{t}=\operatorname{Re}\left(\vec{J} \cdot e^{i \omega t}\right)=\vec{J}_{a} \cdot \cos \omega t-\vec{J}_{b} \cdot \sin \omega t,
$$

де $\vec{J}_{a}=R_{e}(\vec{J})$, и $\vec{J}_{b}=I_{m}(\vec{J})$ - відповідно дійсна і уявна частини комплексної амплітуди вектора $\vec{J}$, обчисленої за формулами (5), (6).

Для функції $\vec{H}_{t}$ за аналогією з (14), можемо записати:

$$
\vec{H}_{t}=\vec{H}_{a} \cdot \cos \omega t-\vec{H}_{b} \cdot \sin \omega t,
$$

де $\vec{H}_{a}=R_{e}(\vec{H}), \vec{H}_{b}=I_{m}(\vec{H}), R_{e}(\vec{H})$, и $I_{m}(\vec{H})$ - відповідають дійсної та уявної частин комплексної амплітуди напруженості магнітного поля, що обчислюється за формулам (10), (11).

Визначивши, таким чином, величини, що входять у формулу для розрахунку миттєвого значення щільності е.м.с. (13), можемо обчислити інтеграл (12). Після нескладних перетворень 
отримаємо вираз для розрахунку усередненої по періоду змінного струму щільності електромагнітної сили, що діє на рідкий метал:

$$
\vec{f}=\mu_{0}\left(\frac{\vec{J}_{a}}{\sqrt{2}}\right) \times\left(\frac{\vec{H}_{a}}{\sqrt{2}}\right)+\mu_{0}\left(\frac{\vec{J}_{b}}{\sqrt{2}}\right) \times\left(\frac{\vec{H}_{b}}{\sqrt{2}}\right)
$$

де $\vec{J}_{a} / \sqrt{2}=R_{e}(\vec{\jmath}) / \sqrt{2}$ и $\vec{J}_{b} / \sqrt{2}=I_{m}(\vec{\jmath}) / \sqrt{2}$ являють собою дійсну і уявну частини так званого діючого значення комплексної щільності струму відповідно, а $\vec{H}_{a} / \sqrt{2}=R_{e}(\vec{H}) / \sqrt{2}$ и $\vec{H}_{b} / \sqrt{2}=$ $I_{m}(\vec{H}) / \sqrt{2}$ - дійсну і уявну частини діючого значення комплексної напруженості магнітного поля відповідно.

Обчисливши векторні здобутки, отримаємо наступний вираз для визначення вектора $\vec{f}$ в декартовій системі координат:

$$
\begin{gathered}
\vec{f}=f_{x} \vec{e}_{x}+f_{y} \vec{e}_{y}+f_{z} \vec{e}_{z}, \\
f_{x}=-\frac{\mu_{0}}{2}\left(J_{a z} H_{a y}+J_{b z} H_{b y}\right), f_{y}=\frac{\mu_{0}}{2}\left(J_{a z} H_{a x}+J_{b z} H_{b x}\right), \\
f_{z}=\frac{\mu_{0}}{2}\left(J_{a x} H_{a y}+J_{b x} H_{b y}-J_{a y} H_{a x}-J_{b y} H_{b x}\right) .
\end{gathered}
$$

Розподіл щільності електромагнітних сил, розрахований за наведеною вище методикою, може бути використаний для розв'язання задачі динаміки в'язкої рідини у ванні УКП. Якщо така здача вирішується з використанням циліндричної системи координат, то останню раціонально вводити таким чином, щоб початок відліку і напрямок осі "z" в прийнятій нами раніше декартовой і циліндричної системах координат збігалися. Перерахунок вектора об'ємної щільності е.м.с. в циліндричні координати стандартним методом [16] не викликає ускладнень.

\section{Результати досліджень та їх обговорення}

Нижче, представлені результати розрахунково-аналітичної оцінки об'ємної щільності е.м.с. для одно- і трьохелектродного варіантів електродугового нагрівання розплаву на УКП (рис. 1, 2). В обох випадках ємність ковшової ванни становила 60 т, а потужність електродугового модуля - 7,7 МВт.

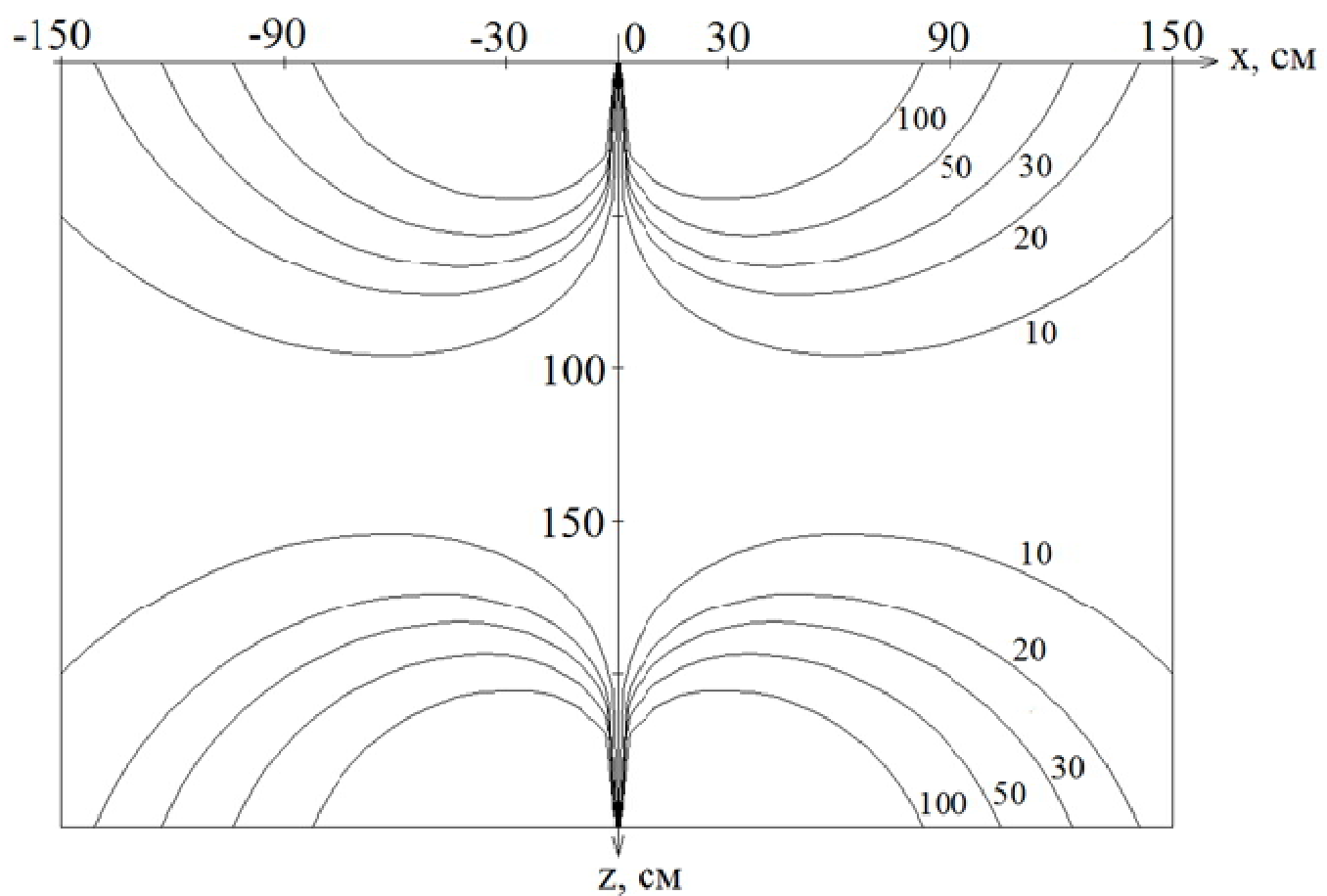

Puc. 1. Розподіл абсолютної величини щільності електромагнітних сил $\left(\mathrm{H} / \mathrm{m}^{3}\right)$ у ванні одноелектродної УКП постійного струму 


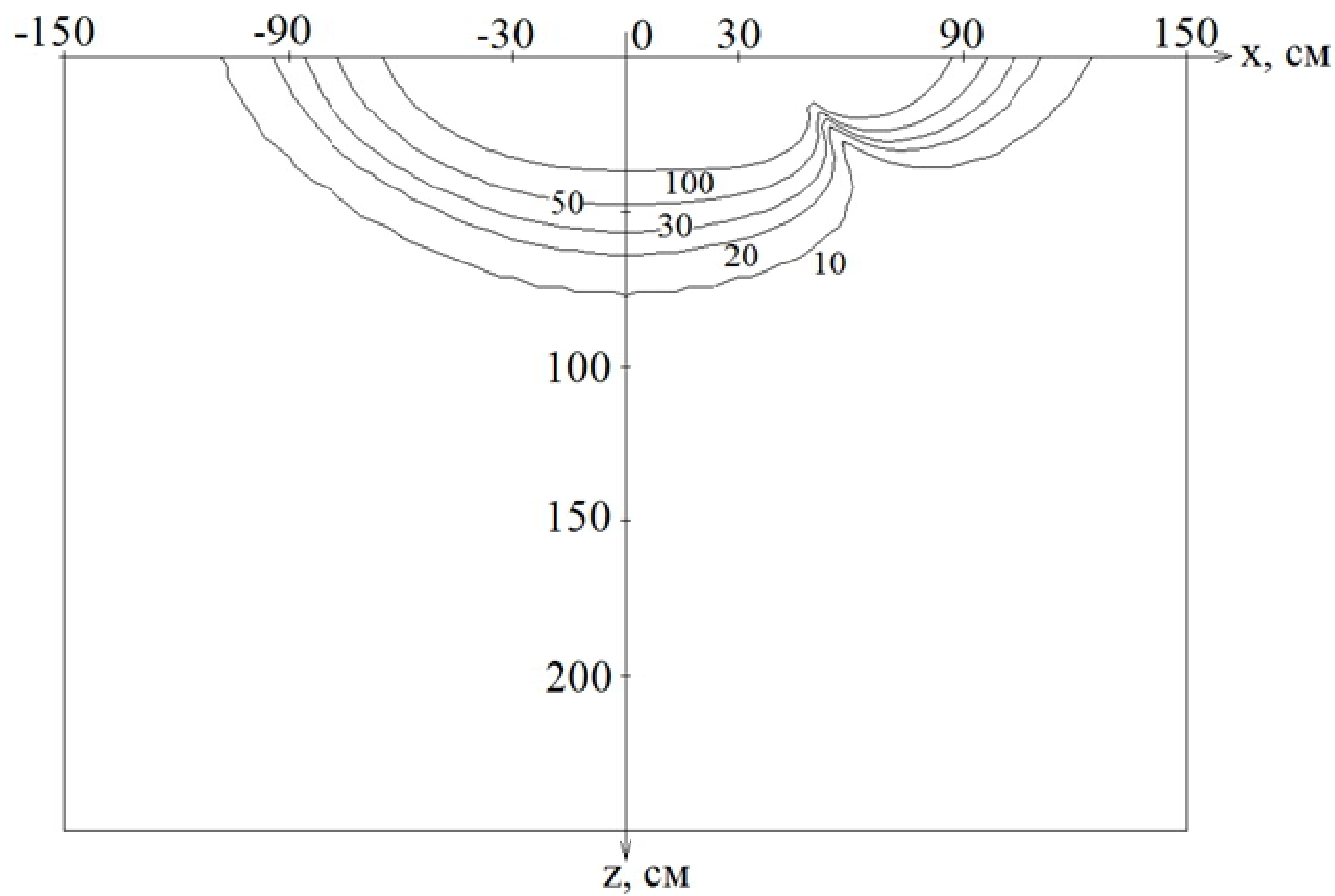

Рис. 2. Розподіл абсолютної величини щільності електромагнітних сил $\left(\mathrm{H} / \mathrm{m}^{3}\right)$ у ванні трьохелектродної УКП змінного струму

Як видно з малюнків 1 і 2, значні щільності електромагнітних сил в металевій ванні, що нагрівається трьохелектродним електродуговим модулем змінного струму, спостерігаються, в основному, у верхній частині ванни (рис.2), що обумовлено локалізацією струму в поверхневих шарах металу, що обробляється. У такій ситуації об'єм металу, на який діють істотні електромагнітні сили, менше, ніж на однодуговій УКП постійного струму [6]. Таким чином, роль електромагнітного фактора в перемішуванні металу, що обробляється, при використанні трьохдугового модуля нагріву буде відносно невеликою і при проведенні теоретичних досліджень впливу різних чинників на технологічні умови і ефективність обробки металу в УКП змінного струму впливом е.м.с. можна знехтувати.

\section{Висновки}

1. Розроблено методику розрахунково-аналітичної оцінки е.м.с. в металевій ванні металургійних агрегатів при електродуговому нагріванні від джерел змінного струму, визначена їх величина при обробці розплаву на УКП ємністю 60 т і потужності дугового модуля 7,7 МВт.

2. Встановлено, що для розглянутих умов експерименту електромагнітні сили, що діють в металі, який обробляється, не мають істотного впливу на перемішування рідкої фази в ковшовій ванні.

\section{Список використаної літератури}

1. Факторы влияния на параметры перемешивания расплава при обработке на установке ковшпечь постоянного тока / В. П. Пиптюк, В. Ф. Поляков, С. Е. Самохвалов и др. // Тр. Х1 междунар. Конгресса сталеплавильщиков - ТРАНСМЕТ 2010, 3-8 октября 2010, Нижний Тагил: М. Чермет информация, 2011. - С. 283-288.

2. Modeling of a DC Electric Arc Furnace - Heat Transfer from the Arc / J. Alexis, M. Ramirez, G. Trapaga, P. Jonsson // The Iron and Steel Institute of Japan International. - 2000. - 40, No. 11. - P. $1089-1097$. 
3. Modeling of a DC Electric Arc Furnace-Mixing in the Bath / M. Ramirez, J. Alexis, G. Trapaga et al. // The Iron and Steel Institute of Japan International. - 2001. - Vol. 41, № 10. - P. 1146-1155.

4. Wang F. Numerical study of dc arc plasma and molten bath in dc electric arc furnace / F. Wang, Z. Jin, Z. Zhu // Ironmaking and Steelmaking. - 2006. - Vol. 33, No 1. - P. 39-44.

5. О перемешивании расплава под действием электромагнитных сил при обработке на установке ковш-печь постоянного тока / В. П. Пиптюк, И. В. Крикент, С. Е. Самохвалов и др. // Бюллетень НТиЭИ «Черная металлургия», ОАО Черметинформация. - 2007. - № 8. - С. 29-33.

6. Влияние постоянного тока на характер массопереноса в металлическом расплаве установки ковш-печь. Часть 1. Действие электромагнитных сил. В. П. Пиптюк, И. В. Крикент, С. Е. Самохвалов и др. // Теория и практика металлургии. - 2007. - № 2-3. - С. 60-64.

7. Влияние постоянного тока на характер массопереноса в металлическом расплаве установки ковш-печь. Часть 2. Модель массопереноса. / В. П. Пиптюк, С. Е. Самохвалов, И. А. Павлюченков и др. // Теория и практика металлургии. - 2007. - № 4-5. - С. 14-17.

8. Влияние постоянного тока на характер массопереноса в металлическом расплаве установки ковш-печь. Часть 3. Гидродинамика ванны. / В. П. Пиптюк, С. Е. Самохвалов, И. А. Павлюченков и др. // Теория и практика металлургии, 2007. - № 6. - С. 3-7.

9. Особенности массопереноса в ванне емкостью 140 т установки ковш-печь постоянного тока / В. П. Пиптюк, С. Е. Самохвалов, В. Ф. Поляков и др. // Фундаментальные и прикладные проблемы черной металлургии: сб. научных трудов / Институт черной металлургии НАН Украины. - Днепропетровск: ИЧМ. - 2012. - вып. 25. - С. 131-138.

10. Численное моделирование сильноточного дугового разряда в установке кош-печь постоянного тока / И.В. Крикент, И. В. Кривцун, В.Ф. Демченко, В.П. Пиптюк // Современная электрометаллургия. - 2013. - № 3 - С. 45-50.

11. Численное исследование гидродинамики расплава в установке ковш-печь постоянного тока / И.В. Крикент, С.Е. Самохвалов, Д.Ю. Кабаков и др. // Современная электрометаллургия. 2014. - № 3. - С. 45-49.

12. Анализ поведения магнитного поля вблизи электродов дуговых печей посредством математического моделирования /Ячиков И.М., Зарецкая Е.М. // Известия ВУЗов. Чёрная металлургия. Электрометаллургия стали и ферросплавов. - 2011. - № 1. - С. 18-21.

13. Генис И. А. Исследование распределения плотности тока на поверхности жидкой металлической ванны и тока между кристаллизатором и слитком в одноэлектродных печах ЭШП / И. А. Генис, И. В. Пентегов // Специальная электрометаллургия. - 1981. - Вып. 45. - С. 40-46.

14. Тарасов В. А. Аналитический расчет растекания тока по ванне жидкого металла от одиночного электрода в шлаке / В. А. Тарасов, Ю. М. Миронов // Электрический расчет в электротехнологических установках. - Чебоксары: Чувашский гос. Ун-т им. И. Н. Ульянова, 1971. С. $48-56$.

15. Атабеков Г.И. Основы теории цепей. М.: «Энергия». - 1969. -424 с.

16. Бронштейн М.С. Справочник по математике для инженеров и учащихся ВТУЗов / М.С. Бронштейн, К.А. Семендяев. - М: Наука. - 1986. -544 с. 